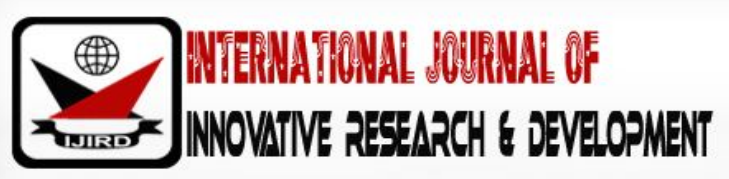

ISSN 2278 - 0211 (Online)

\section{Aqueous Extract of Capsicum Frutescens Exhibits Saturation Phenomenon in Gastric Acid Secretion}

\author{
\begin{tabular}{|c|}
\hline Dr. Nndunno Akwaras \\
Senior Registrar, Department of Family Medicine, Federal Medical Centre, Nigeria \\
Dr. Julie Ibu \\
Chief Inspector, National Youth Service Corps, Benue State Secretariat, Nigeria \\
Christian Onahinon \\
Masters Student, Department of Physiology, Benue State University, Nigeria \\
Dr. Emmanuel Eru \\
Lecturer, Department of Physiology, College of Health Sciences, Benue State University, Nigeria
\end{tabular}
}

\begin{abstract}
:
The effects of orally ingested substances on gastric function have been the subject of human investigation almost since the discovery of hydrochloric acid in gastric juice by Prout in 1824. Capsicum frutescens is a ubiquitous spice widely consumed in Nigeria, West Africa and many parts of the world. A few studies have been done in Nigeria on Capsicum frutescens but not much has been known on its effect on gastric acid secretion. The present study was carried out to investigate the effect of Capsicum frutescens on gastric acid secretion. 48 male and female albino Wistar rats weighing between 200-300 g were randomly allocated to 6 groups with 8 rats per group. Aqueous extract of Capsicum frutescens prepared after the method of Alnaqueeb (1996) was administered through a gastric fistula at the fundus. 10\%, 20\%, 30\% of $\mathrm{LD} 50$ and supramaximal doses of $10 \mathrm{mg}, 20 \mathrm{mg}, 30 \mathrm{mg}, 40 \mathrm{mg}, 50 \mathrm{mg}, 60 \mathrm{mg}, 70 \mathrm{mg}$ and $80 \mathrm{mg}$ per $100 \mathrm{~g}$ body weight of the aqueous extract were administered. Gastric acid was measured after the method of Ghosh and S child 1958 as modified by Ibu (1987). The result of gastric acid secretion on administration of $10 \%$ of $\mathrm{LD}_{50}$ dose in $\mathrm{mmol} / \mathrm{L} /$ hour for basal acid output (BAO) was $16.2 \pm 0.01$ and was $13.7 \pm$ $0.12,15.4 \pm 0.07,16.2 \pm 0.06,18.1 \pm 0.04,18.6 \pm 0.03,18.6 \pm 0.10$ at 40, 50, 60, 70, 80 and 90 minutes respectively. It was observed that gastric acid secretion increased stepwise and was time dependent rising to a crescendo between 50 and 70 minutes. Thereafter the secretory response rose to a plateau. Similar responses occurred at all doses studied, indicating saturation phenomenon of the secretory capacity of the stomach. It is concluded that Capsicum frutescens exhibits saturation phenomenon in gastric acid secretion in the albino Wistar rat.
\end{abstract}

Keywords: Gastric acid secretion, capsicum frutescens, saturation phenomenon

\section{Introduction}

Gastric acid is component of gastric juice secreted in the stomach. It is a secretory product of the parietal or oxyntic cell mainly concentrated in the fundic area of the stomach. Parietal cells secrete at a concentration of roughly $160 \mathrm{mM}$ (equivalent to a $\mathrm{pH}$ of 0.8 ) when stimulated. The other cells of the stomach are the chief cells, mucus cells and neuroendocrine cells (Helander, 1993).

The study of gastric acid secretion has been on for quite a long time. Beaumont (1822), Heidenhain (1834 - 1897), Edkins (1905), Pavlov (1910), Ivy (1928), Babkin (1930), and Gregory and Tracy (1963) were among the many 19th and 20th century investigators concerned with the mechanism of acid secretion in stomach (Ibu, 1987) The effects of orally ingested substances among which is Capsicum frutescens on gastric function have been the subject of human investigation almost since the discovery of hydrochloric acid in gastric juice by Prout (1824). Capsicum frutescens commonly called Tatase in Nigerian market is widely consumed in Nigeria, West Africa and many other parts of the world. It contains capsaicin which is 8-methyl-N-vanillyl-6-nonenamide as the main principle and it is a pungent phenolic chemical (Gonzalez et al., 1998, Kim et al., 2009). Other capsaicinoids found in Capsicums include dihydrocapsaicin, homocapsaicin, homodihydrocapsaicin and norhydrocapsaicin. Vitamins A and C, fatty acids, carotene, flavonoids, thiamine, citric, tartaric, malic and tannic acids have also been found in the fruit (Alevizes et al., 2007). The effects of Capsicum frutescens on gastric acid secretion have not been widely explored. 


\section{Materials and Methods}

Capsicum frutescens were bought from the local market (Wadata Market) in Makurdi, Benue State, Nigeria. It was identified by a taxonomist in the department of Botany, Faculty of Sciences of Benue State University, Nigeria and a specimen voucher deposited in their herbarium.

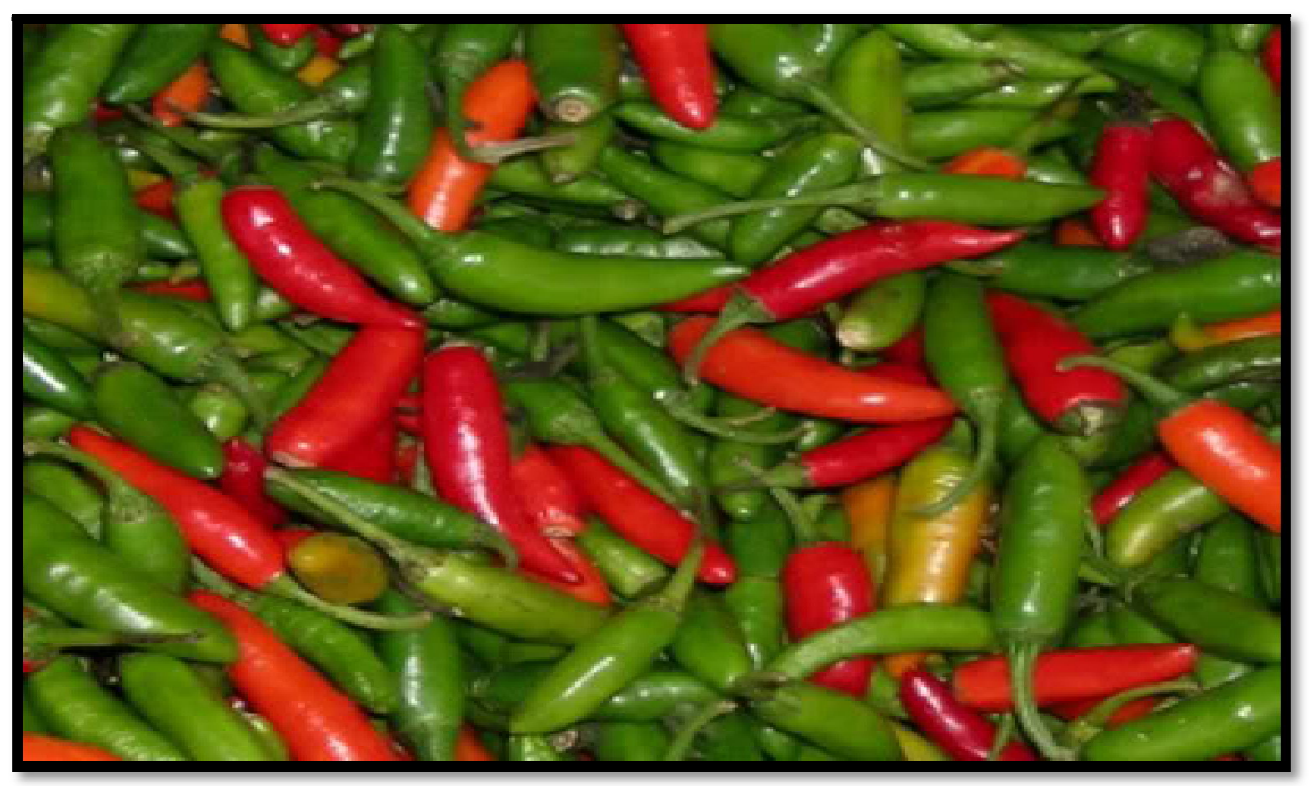

Figure 1: Specimen of Capsicum Frutescens Fruit

\subsection{Drugs and Chemicals}

Analytical grade Sodium hydroxide $(\mathrm{NaOH})$, Sodium Chloride $(\mathrm{NaCl})$ and phenolphthalein made by May and Baker (Dagenham, England) and urethrane made by Sigma Chemical Co. (Poole, UK). ANIMALS

Forty-Eight Albino Wistar rats weighing 200-300g of both sexes were obtained from the animal house of the College of Health Sciences, Benue State University, Makurdi and nursed under the same conditions in the animal house research laboratory. They were subjected to a 12-hour light and dark photic cycle. And fed on normal rat chow (Pfizer Limited, Kaduna, Nigeria) and given water ad libitum. Permission for the use of the animals was obtained from the Animal Ethics Committee of Benue State University Makurdi, Nigeria.

\subsection{Preparation of the Extract}

The aqueous extract preparation was being modified following the method of Alnaqeeb et al., (1996). 50g (Wt 1) of the fresh fruit was thoroughly washed and placed in clean beakers (Pyrex, $500 \mathrm{ml}$ ). It was homogenized in $75 \mathrm{ml}$ (V1) of cold sterile $0.9 \%$ saline in the presence of some crushed ice using an electric blender. The homogenous mixture was filtered with Whatman no1 filter paper and centrifuged at $2000 \mathrm{rev} / \mathrm{min}$ for 10 minutes and the clear supernatant was collected and volume noted (V2). The volume of the wet residue was noted as Wt 2 . The volume of the supernatant was subtracted from the volume of the cold saline used in homogenization (V1 - V2) or V3 which was noted as Wt 3. The yield of each of the three preparations was used to determine the stock concentration.

stock concentration $=\mathrm{Wt} 1-(\mathrm{Wt} 2+\mathrm{Wt} 3) \div \mathrm{V} 2$

$$
\text { [ yield }=\mathrm{Wt1}-(\mathrm{Wt} 2-\mathrm{Wt} 3)]
$$

The above formula was used to calculate the stock concentration of each which was then stored in refrigerator until used. The required amount was administered in $\mathrm{mg} /$ 100-gram body weight of each animal.

$50 \mathrm{~g}$ of Capsicum frutescens contains $0.206 \pm 0.02 \mathrm{~g}$ of capsaicin (Ekwere et al., 2016). Oral LD 50 values of Capsaicin are 161.2 $\mathrm{mg} / \mathrm{kg}$ (16.12 mg / $100 \mathrm{~g}$ body weight) and $148.1 \mathrm{mg} / \mathrm{kg}$ (14.81 mg / $100 \mathrm{~g}$ body weight) for male and female rats respectively (Saito et al., 1996).

The above information from literature was to determine the dose of capsicum extract that will be administered.

\subsection{Animal Grouping and Experimental Design}

48 Wistar rats weighing between 200 - 300 grams were randomly assigned to six groups consisting of 8 rats each as follows: 
- Group 1- Control group for Capsicum frutescens which were administered normal saline.

- Group 2- were administered 10\% LD 50 of Capsicum frutescens.

- Group 3- were administered 20\% LD 50 of Capsicum frutescens.

- Group 4- were administered $30 \% \mathrm{LD}_{50}$ of Capsicum frutescens.

- Group 5- Control group for successive supramaximal doses of Capsicum frutescens which were administered normal saline.

- Group 6 - were administered successive supramaximal doses of Capsicum frutescens of 10mg, 20mg, 30mg, 40mg, $50 \mathrm{mg}, 60 \mathrm{mg}, 70 \mathrm{mg}$ and $80 \mathrm{mg}$

\subsection{Experimental Protocol}

After a 12 hour fast, each animal was anaesthetized with 25 \% Ethyl Carbonate (urethane) at a dose of $0.6 \mathrm{ml} / 100 \mathrm{~g}$ body weight intraperitoneally.

Tracheostomy was performed. A nasogastric tube was passed. A duodenostomy was performed and normal saline was used as gastric lavage to wash out the debris from the stomach until clear effluent was obtained. A duodenogastric canula was passed and ligated insitu for subsequent collection of gastric acid secretion. 10 minutes aliquot samples were collected from the duodenal canula. A gastric fistula was created in the fundus with insertion of a 2-way canula to allow the administration of the extract. The aliquots were each titrated to a phenolphthalein end point using $0.01 \mathrm{M} \mathrm{NaOH}$ and the acid output or concentration is calculated as described by Ibu (1986), Ibu and Ebieme (1993) as follows:

Where Normality $=$ Molarity

$\mathrm{MA} V A=\mathrm{MB} V B$

$\mathrm{MA}=\quad \mathrm{MB} \mathrm{VB} \div \mathrm{VA}$

Where,

$\mathrm{MB}=$ Molarity of base known $(0.01 \mathrm{~N})=10 \mathrm{mMol}$

$\mathrm{VB}=$ Volume of base known (titrate of $\mathrm{NaOH}$ ) used

$\mathrm{VA}=$ Volume of acid (effluent volume) $=10 \mathrm{ml}$

Substituting for $\mathrm{MB}$ and VA

$\mathrm{MA}=10 \times \mathrm{VB} \div 10$

Therefore $\mathrm{MA}=\mathrm{VB}$

Acid output $/ 10$ minutes $=\mathrm{VB} \mathrm{mMol} / \mathrm{L} / 10 \mathrm{mins}$

Acid output per hour = VB x $6 \mathrm{mMol} / \mathrm{L} /$ hour (Ibu, 1987).

The results were analyzed for graphics and statistics using SPSS version 23. Statistical differences were accepted at $95 \%$ Confidence limit when $\mathrm{P} \varangle 0.05$.

\section{Results}

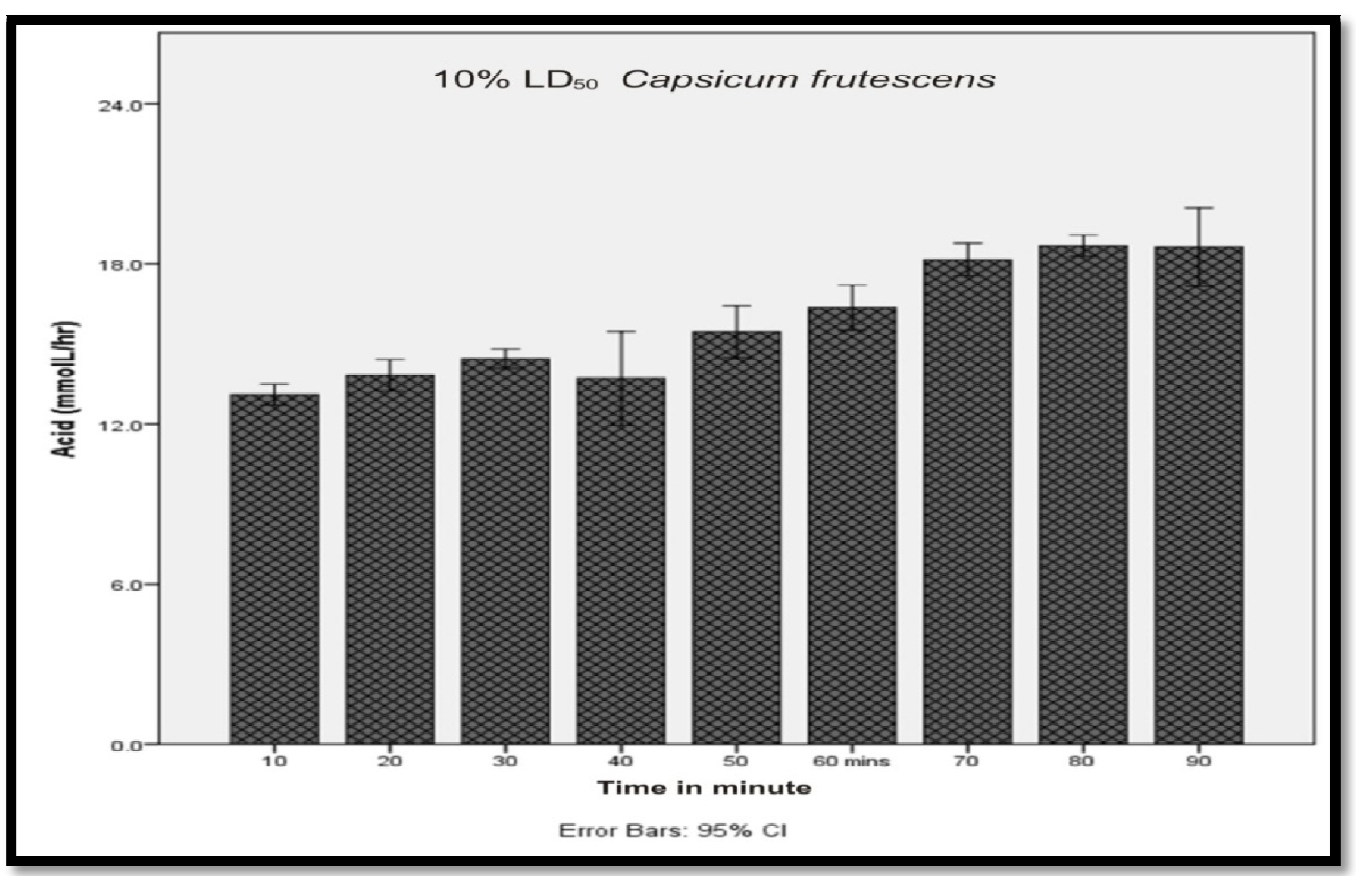

Figure 2 
Figure 2 shows the result following the administration of $10 \%$ of $\mathrm{LD}_{50}$. The acid produced increased steadily until it reached a plateau from 70 to 90 minutes exhibiting saturation phenomenon.

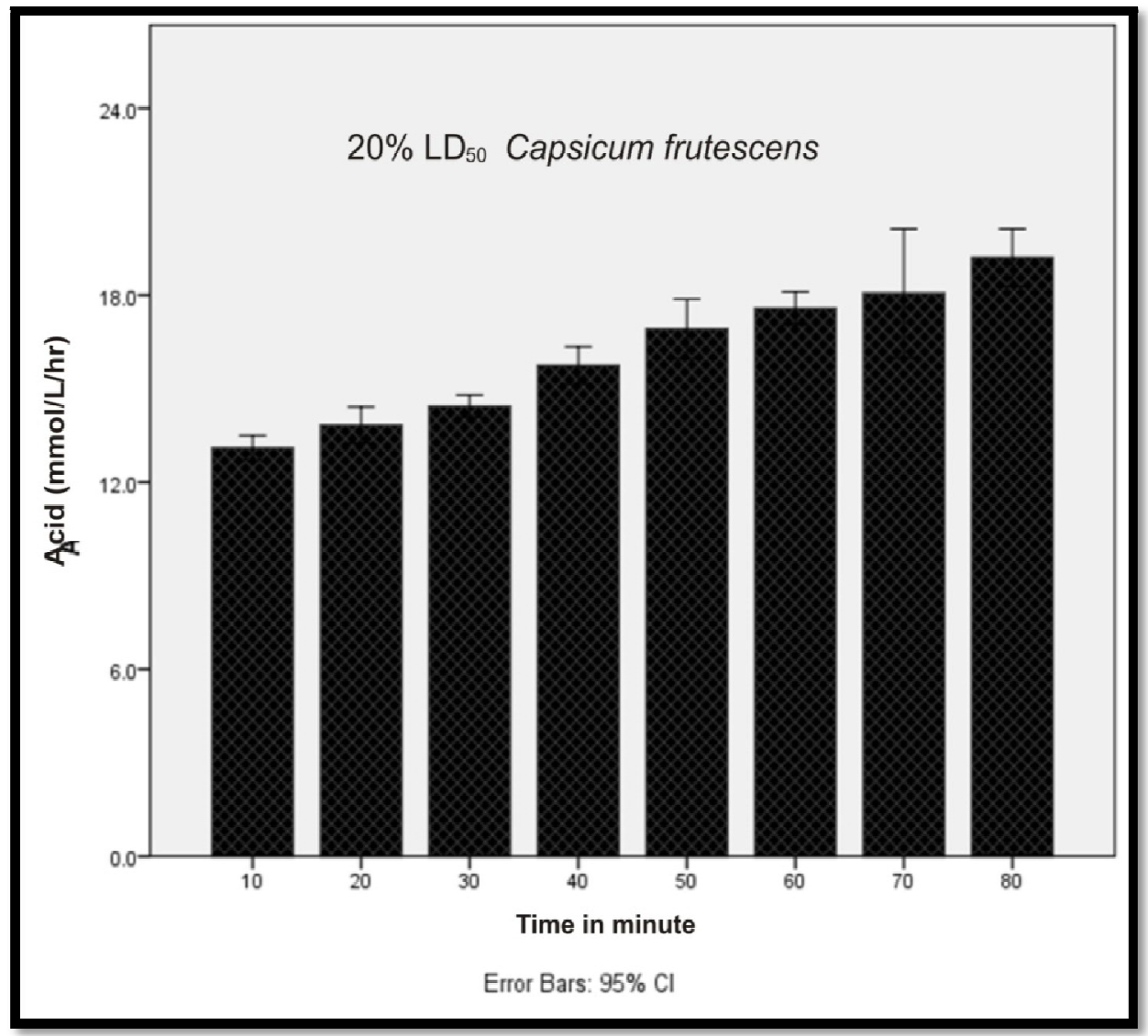

Figure 3

Figure 3- A graph showing the effect of administering a dose of $20 \%$ of $\mathrm{LD}_{50}$ of Capsicum frutescens extract. Saturation phenomenon is observed from 70 to 80 minutes.

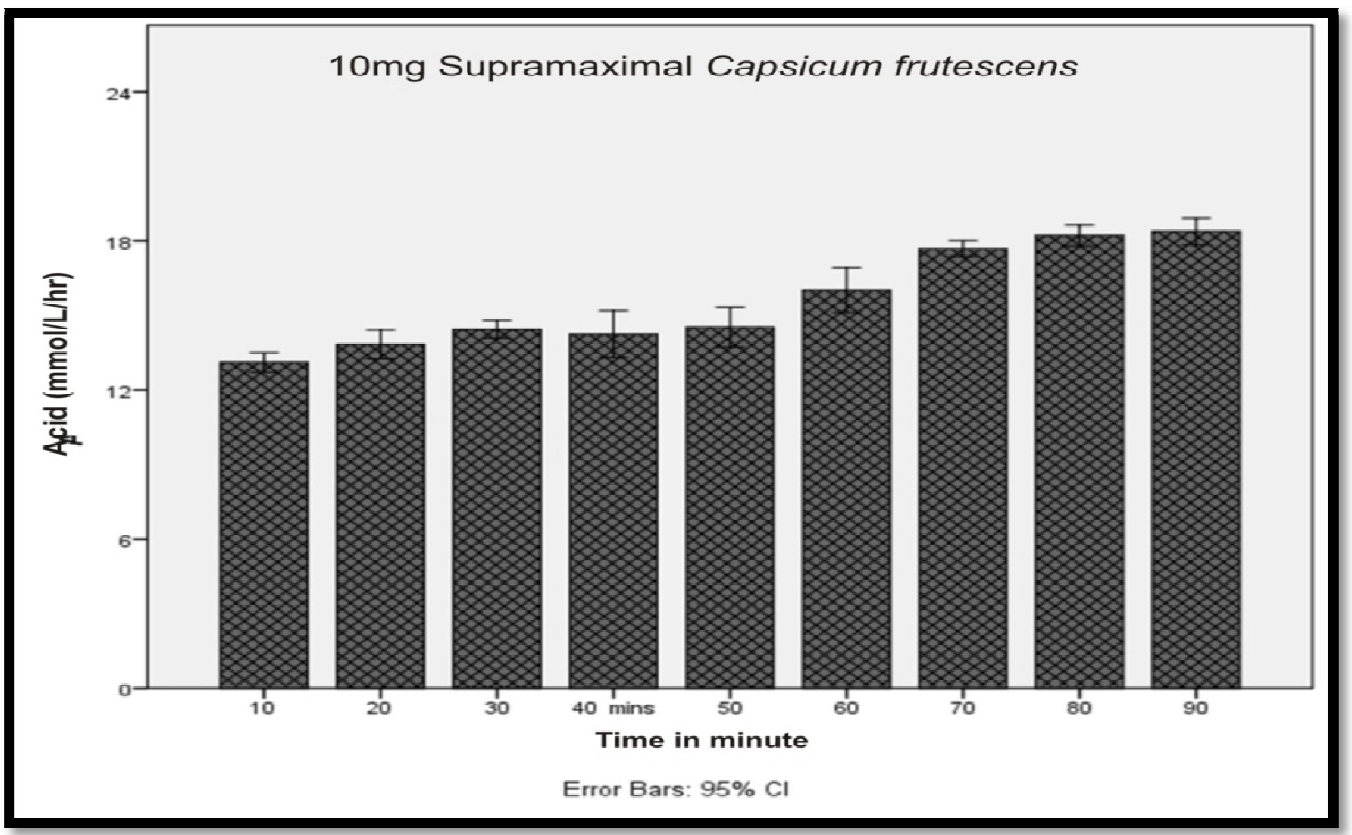

Figure 4 
Figure 4 shows the graph of administration of $10 \mathrm{mg}$ supra maximal dose of Capsicum frutescens. A saturation phenomenon is observed at 70 to 90 minutes.

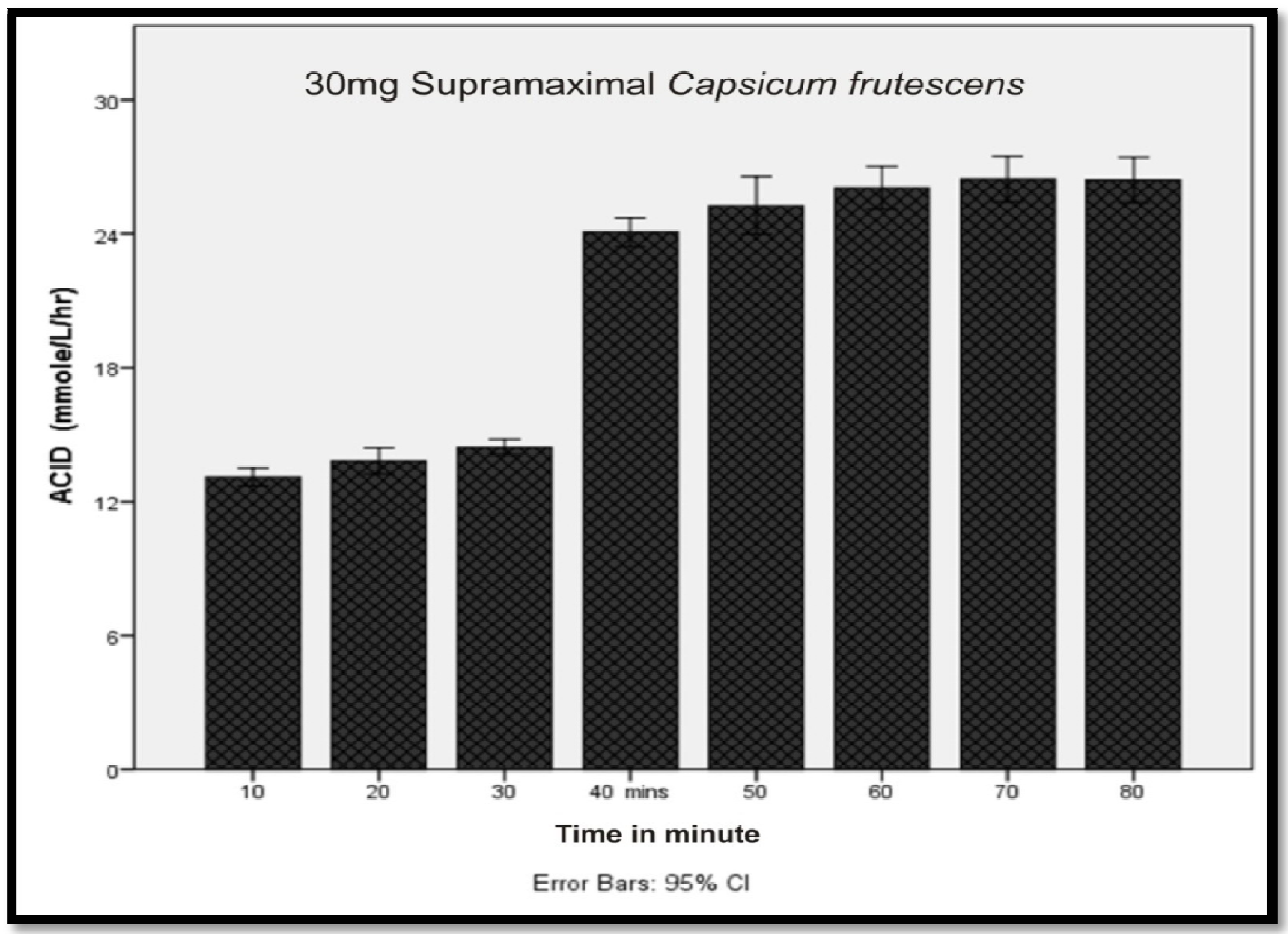

Figure 5

Figure 5- Graph showing the administration of 30mg supramaximal dose. A saturation phenomenon is observed from 60 to 80 minutes.

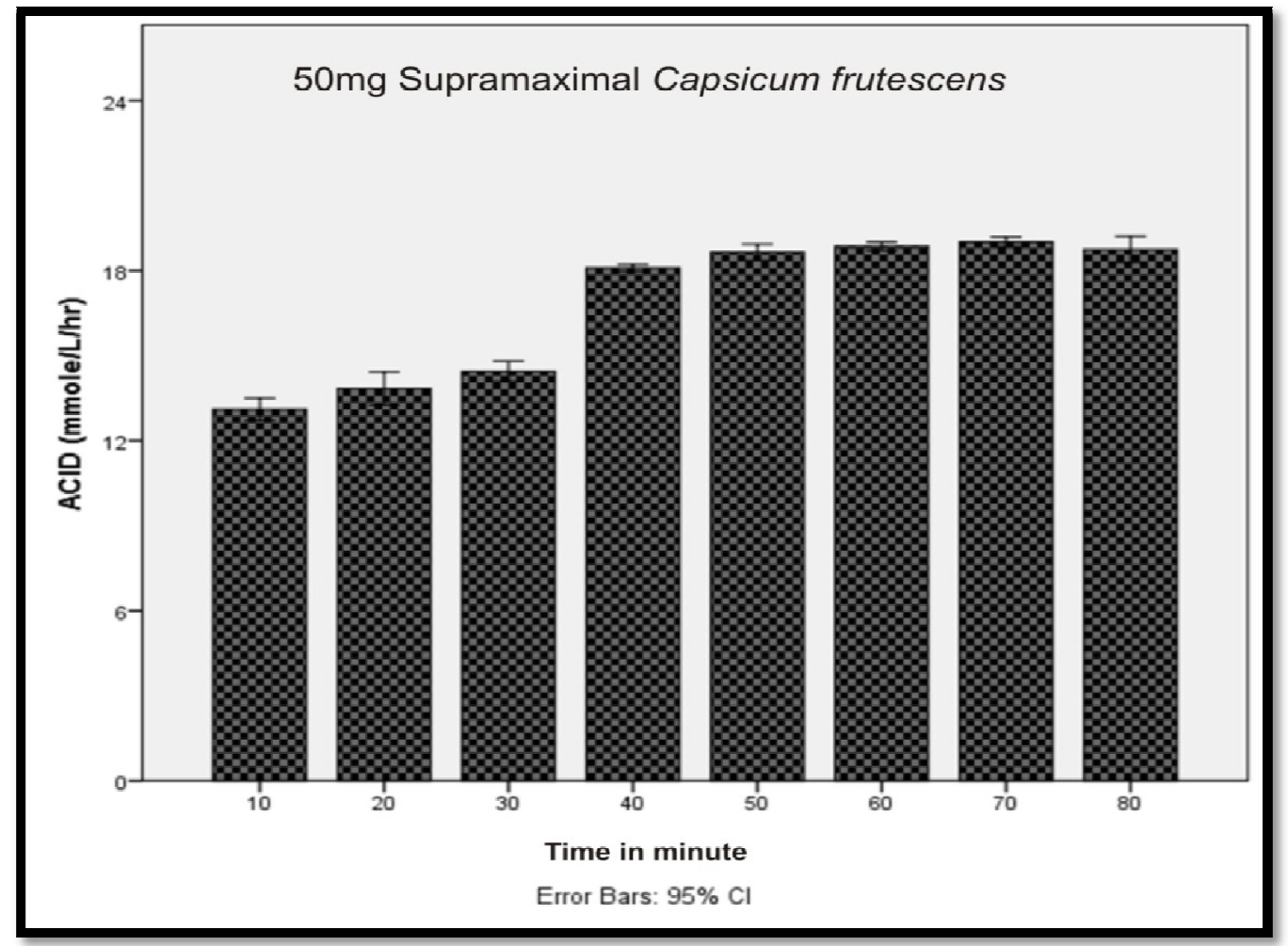

Figure 6 
Figure 6- Shows a graph of administration of $50 \mathrm{mg}$ supramaximal dose of Capsicum frutescens. Saturation phenomenon is seen from 50 to 80 minutes.

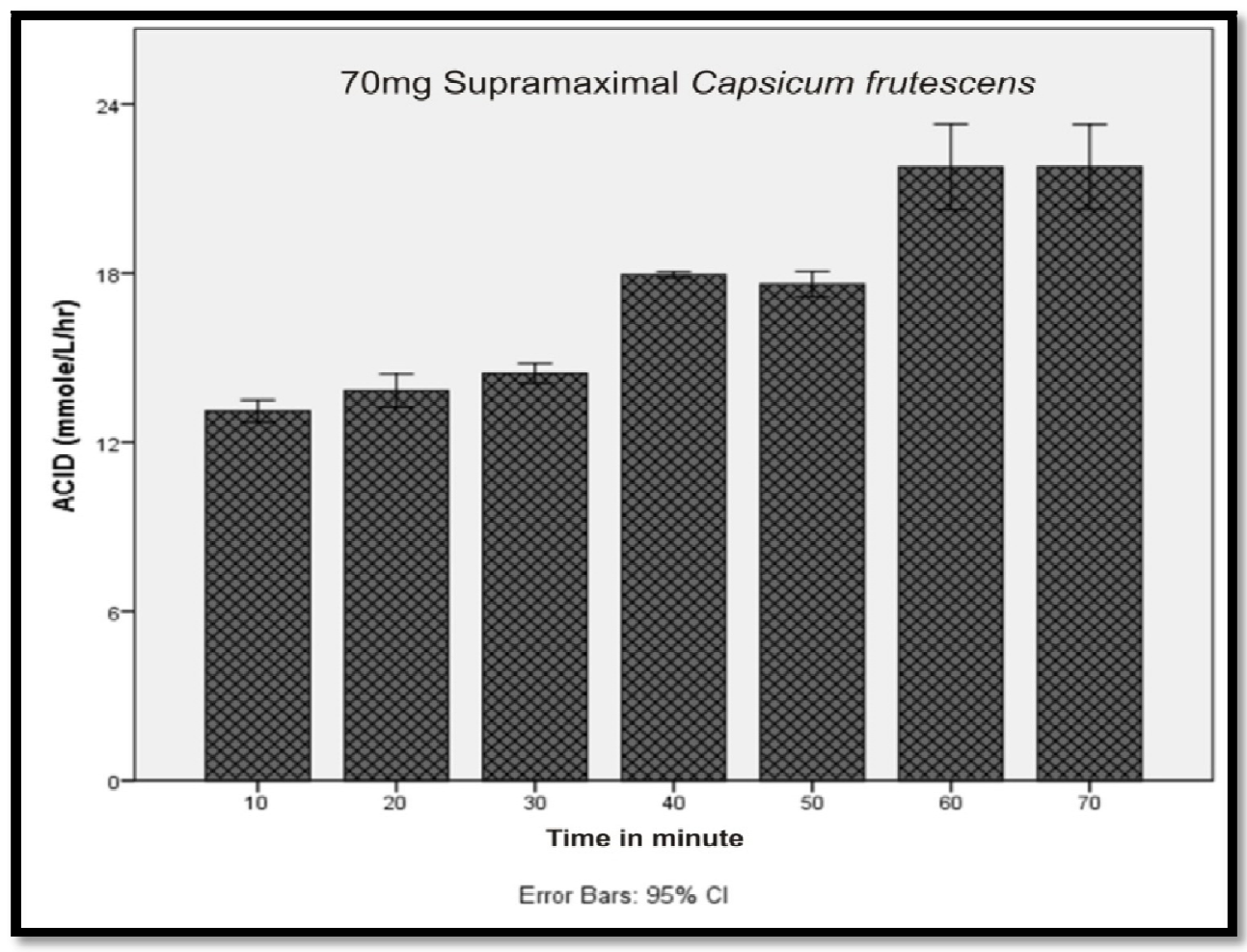

Figure 7

Figure 7- Shows a graph of administration of $70 \mathrm{mg}$ supramaximal dose of Capsicum frutescens. Saturation phenomenon is seen from 60 to 70 minutes.

There was statistically significant difference between BAO and the acid secretion at 40, 50, 60, 70, 80 and 90 minutes $(p<0.01)$. Also, the difference between the BAO and the acid secretions at the saturation levels of the different doses was statistically significant $(\mathrm{p}<0.01)$.

\section{Discussion}

Hot peppers such as Capsicum frutescens contain capsaicin as the active principle. Capsaicin exerts it activity through the capsaicin-sensitive sensory afferent nerves. Capsaicin-sensitive afferent neurons play a central role in the neuronal mechanism of the stomach (Holzer, 1998). These afferent neurons control several actions such as mucosal blood flow, secretion, motility and maintenance of the mucosal integrity of the stomach (Holzer and Sametz; 1986 Holzer, 1998; Takeuchi et al., 1991, 1992). Capsaicin has several actions, its effects on gastric acid secretion however attracts a lot of attention. Some studies report that low-dose capsaicin can decrease gastric acid secretion while high-dose may increase gastric acid secretion (Imatake et al., 2009, Mozsik et al., 1999).

In this study a steady rise in acid was observed with increasing doses of the pepper. The samples were collected at 10 minutes interval and at 70-90 minutes the acid measured reached a plateau simulating a saturation phenomenon. Several natural phenomena have been described to exhibit saturation phenomena. These include ligand binding, enzyme kinetics, facilitated diffusion, predator-prey behavior, bacterial culture growth rate, infection transmission and surface adsorption (Gordon, 2010).

It is concluded that there is saturation phenomenon exhibited by Capsicum frutescens stimulated gastric acid secretion in albino Wistar rats. Public health education is advocated to give people awareness of the findings in this research. Advice should be given to people to be careful in the use of pepper in preparing their meals by using this pepper in moderation to avoid saturation phenomenon.

\section{References}

i. Alnaqueeb MA, Thompson M, Bordia T, and Ali M. (1996). Histopathological effects of garlic on liver and lungs of rats. Toxicol Lett. 85: 157-164.

ii. Alevizes A, Mihas C, Mariolis A, Larios G. (2007). Insulin secretion and capsaicin. Am J Clin Nutr. 85(4):1165-1166.

iii. Ekwere MR, Udoh DE. (2016). Extraction and comparative analysis of moisture and capsaicin contents of capsicum peppers. J pain Relief 5:268. 
iv. Ghosh MN and Schild HO. (1958). Continuous recording of gastric acid secretion in Rat. Brit J. Pharm 13: 54-61.

v. Gordon R K. (2010). Saturation Behavior: a general relationship described by a simple second-order differential equation. Theor Biol Med Model. 2010; 7: 11.

vi. Gonzalez R. (1998). Effect of capsaicin-containing red pepper sauce suspension on upper gastrointestinal motility in healthy volunteers. Dig Dis Sci. 43(6):1165-1171.

vii. Helander HF, Keeling DJ. (1993). Cell biology of gastric acid secretion. Bailieres Clin Gastroenterol. 7(1):1-21.

viii. Holzer P and Sametz W (1986). Gastric mucosal protection against ulcerogenic factors in the rat mediated by capsaicin-sensitive afferent neurons. Gastroenterology 91:975-987.

ix. Holzer P (1998). Neural emergency system in the stomach. Gastroenterology 114: 823-839.

x. Ibu JO, Nwokediukko SC, Okpara E (1986). The nature of stimulation of gastric acid secretion by cola nitida using antimuscarinic drugs. Process West Soc Gastroent. 1:7-8.

xi. Ibu JO, Irozuru MN, Dakar DD (1993). Effects of Capsicum annum, Capsicum frutescens and Tamarindus indica (African peppers) on gastric acid secretion. Nig Med J. Vol 24(suppl): 9-12.

xii. Ibu JO. (1987). Synopsis of medical physiology. Manchester Amazon Press.

xiii. Imatake K, Matsui T, Moriyama M. (2009). The effect and mechanism of action of capsaicin on gastric acid output. Journal of Gastroenterology 44(5):396-404.

xiv. Kim KS, Kim KN, Hwang KG, Park CJ. (2009). Capsicum plaster at the Hegu point reduces postoperative analgesic requirement after orthognathic surgery. Anesth Analg. 108(3):992-996.

xv. Mozsik G1 , Debreceni A , Abdel-Salam OM , Szabo I , Figler M, Ludany A , Juricskay I , Szolcsanyi J. (1999). Small doses of capsaicin given intragastrically inhibit gastric basal acid secretion in healthy human subjects. J Physiol Paris.13(4) 54-60.

xvi. Prout W. (1824). On the nature of acid and saline matters usually existing in stomach of animals. Phil Trans. 14:45-9.

xvii. Saito A, Yamamoto M.(1996). Acute oral toxicity of capsaicin in mice and rats. J Toxicol Sci. 21(3):195-200.

xviii. Takeuchi K, Matsumoto J, Ueshima K, and Okabe S (1991) Role of capsaicin sensitive afferent neurons in alkaline secretory response to luminal acid in the rat duodenum. Gastroenterology 101:954-961.

xix. Takeuchi K, Ueshima K, Matsumoto J, and Okabe S (1992). Role of capsaicin sensitive sensory nerves in acid-induced bicarbonate secretion in rat stomach. Dig Dig Sci 37:737-743. 